\title{
Presynaptic Kainate Receptor Activation Is a Novel Mechanism for Target Cell-Specific Short-Term Facilitation at Schaffer Collateral Synapses
}

\author{
Hua Yu Sun and Lynn E. Dobrunz \\ Department of Neurobiology, Civitan International Research Center, and Evelyn F. McKnight Brain Institute, University of Alabama at Birmingham, \\ Birmingham, Alabama 35294
}

\begin{abstract}
Target cell-specific differences in short-term plasticity have been attributed to differences in the initial release probability of synapses. Using GIN (GFP-expressing inhibitory neurons) transgenic mice that express enhanced green fluorescent protein (EGFP) in a subset of interneurons containing somatostatin, we show that Schaffer collateral synapses onto the EGFP-expressing somatostatin interneurons in CA1 have very large short-term facilitation, even larger facilitation than onto pyramidal cells, in contrast to the majority of interneurons that have little or no facilitation. Using a combination of electrophysiological recordings and mathematical modeling, we show that the large short-term facilitation is caused both by a very low initial release probability and by synaptic activation of presynaptic kainate receptors that increase release probability on subsequent stimuli. Thus, we have discovered a novel mechanism for target cell-specific short-term plasticity at Schaffer collateral synapses in which the activation of presynaptic kainate receptors by synaptically released glutamate contributes to large short-term facilitation, enabling selective enhancement of the inputs to a subset of interneurons.
\end{abstract}

Key words: GIN mice; somatostatin; mathematical model; presynaptic; paired-pulse facilitation; release probability; interneuron; CA1; hippocampus

\section{Introduction}

Excitatory axons show target cell-specific short-term plasticity, both in the neocortex (Thomson, 1997; Markram et al., 1998; Reyes et al., 1998; Rozov et al., 2001; Koester and Johnston, 2005) and in hippocampus (Ali et al., 1998; Scanziani et al., 1998; Toth et al., 2000; Losonczy et al., 2002; Sun et al., 2005). Proposed mechanisms underlying this include differences in the initial vesicular release probability (Rozov et al., 2001; Sun et al., 2005) and the initial readily releasable vesicle pool size (Sun et al., 2005), resulting in differences in the initial synaptic release probability (Rozov et al., 2001; Koester and Johnston, 2005; Sun et al., 2005).

Excitatory synapses onto GABAergic interneurons are also heterogeneous both in the cortex (e.g., Rozov et al., 2001) and in hippocampus (e.g., Sun et al., 2005). In the hippocampus, shortterm plasticity of Schaffer collateral synapses does not correlate with interneuron morphology (Sun et al., 2005), in contrast to interneurons in cortex (Reyes et al., 1998; Rozov et al., 2001; Koester and Johnston, 2005). Hippocampal interneurons have instead been proposed to form functional subgroups identifiable by their neurochemical content such as neuropeptides and cal-

Received June 28, 2006; revised Sept. 8, 2006; accepted Sept. 8, 2006

This work was supported by National Institutes of Health Grants R01 MH65328 (L.E.D.), MRRC P30-HD38985, and P01-HD38760, and a Civitan Emerging Scholars Grant (H.Y.S.) from the University of Alabama at Birmingham Civitan International Research Center. We thank Drs. Lori McMahon and Smadar Lapidot for their helpful comments on this manuscript and Dr. Susan Lyons and Brandon Walters for their technical assistance.

Correspondence should be addressed to Lynn E. Dobrunz, 1825 University Boulevard, SHEL 902, Birmingham, AL 35294.E-mail:dobrunz@uab.edu.

DOI:10.1523/JNEUROSCI.2746-06.2006

Copyright $\odot 2006$ Society for Neuroscience $\quad 0270-6474 / 06 / 2610796-12 \$ 15.00 / 0$ cium binding proteins (Freund and Buzsaki, 1996). We predict that these different functional subgroups of interneurons will have differences in the short-term plasticity of their synaptic inputs. However, evidence linking short-term plasticity of Schaffer collateral synapses to the neurochemical content of hippocampal interneurons is lacking.

Here, we investigate short-term plasticity of Schaffer collateral synapses using the GFP-expressing inhibitory neurons (GIN) line of transgenic mice that express enhanced green fluorescent protein (EGFP) in a subset of interneurons containing the neuropeptide somatostatin (SOM) (Oliva et al., 2000). Because it can be difficult to assess the neurochemical content of cells after prolonged whole-cell recordings, this enables us to investigate the properties of a specific subset of interneurons easily identifiable by their expression of EGFP. Because previous immunohistochemical characterization has shown that not all somatostatin interneurons in GIN mice express EGFP (Oliva et al., 2000) (the EGFP interneurons are a subset of somatostatin interneurons), we refer to them here as EGFP-expressing SOM interneurons.

We have previously shown that Schaffer collateral synapses onto stratum (s.) radiatum interneurons in hippocampal slices from rats are heterogeneous, having either small paired-pulse facilitation or paired-pulse depression (Sun et al., 2005). In the GIN mice, we find that Schaffer collateral synapses onto all EGFP-expressing SOM interneurons in s. radiatum are alike in showing large short-term facilitation, even larger than facilitation of Schaffer collateral synapses onto CA1 pyramidal cells. In contrast, Schaffer collateral synapses onto the majority of interneu- 
rons show minimal facilitation or short-term depression. The large facilitation is attributable in part to a low initial release probability and in part to the synaptic activation of kainate receptors that act presynaptically to increase the release probability on subsequent pulses. Thus, we have discovered a novel mechanism for target cell-specific short-term plasticity in which the activation of presynaptic kainate receptors by synaptically released glutamate contributes to extremely large short-term facilitation, enabling selective enhancement of the inputs to a subset of interneurons.

\section{Materials and Methods}

Slice preparation. Male GIN transgenic mice (10-15 d old) that express EGFP in a subset of interneurons containing somatostatin (Oliva et al., 2000) were anesthetized with halothane (4\%) and decapitated, and their brains were removed rapidly. Coronal slices of the brain, $400 \mu \mathrm{m}$ thick, were cut using an oscillating tissue slicer (EMS-4000; Electron Microscopy Sciences, Fort Washington, PA) or a vibrating microtome (VT1000S; Leica, Bannockburn, IL). Slicing and dissection of the hippocampi were done in ice-cold $\left(1-3^{\circ} \mathrm{C}\right)$ dissecting solution containing the following (in mM): $120 \mathrm{NaCl}, 3.5 \mathrm{KCl}, 0.7 \mathrm{CaCl}_{2}, 4.0 \mathrm{MgCl}_{2}, 1.25$ $\mathrm{NaH}_{2} \mathrm{PO}_{4}, 26 \mathrm{NaHCO}_{3}$, and 10 glucose, bubbled with $95 \% \mathrm{O}_{2} / 5 \% \mathrm{CO}_{2}$, $\mathrm{pH}$ 7.35-7.45. Slices were stored at room temperature in a holding chamber containing the dissecting solution and bubbled with $95 \% \mathrm{O}_{2} / 5 \% \mathrm{CO}_{2}$ for $>0.5 \mathrm{~h}$ before recording.

Electrophysiology. During the experiment, slices were held in a submersion recording chamber perfused with external recording solution composed of the following (in mM): $120 \mathrm{NaCl}, 3.5 \mathrm{KCl}, 2.5 \mathrm{CaCl}_{2}, 1.3 \mathrm{MgCl}_{2}$, $1.25 \mathrm{NaH}_{2} \mathrm{PO}_{4}, 26 \mathrm{NaHCO}_{3}$, and 10 glucose. The solution was bubbled with $95 \% \mathrm{O}_{2} / 5 \% \mathrm{CO}_{2}, \mathrm{pH} 7.35-7.45$. Picrotoxin (100 $\left.\mu \mathrm{M}\right)$ was added to the external solution to block inhibitory synaptic responses mediated by $\mathrm{GABA}_{\mathrm{A}}$ receptors; the CA3 region of hippocampus was removed to prevent recurrent excitation. Except for experiments measuring NMDA receptor mediated EPSCs (see Figs. 2, 4G-I, 5A-C), the solution also contained $100 \mu \mathrm{M}$ D-2-amino-5-phosphonopentanoic acid (APV) to block NMDA receptor-mediated currents and prevent postsynaptic shortterm plasticity, as well as to prevent long-term potentiation (LTP) and long-term depression (LTD). All experiments were performed at room temperature $\left(\sim 24^{\circ} \mathrm{C}\right)$ except for the warm temperature experiments in Figure $1, E$ and $F$, that were performed at $33^{\circ} \mathrm{C}$. APV, 4-(8-methyl- $9 \mathrm{H}$ 1,3-dioxolo[4,5,-h] [2,3]benzodiazepine-5-yl)-benzenamine hydrochloride (GYKI 52466), and 6,7-dinitroquinoxaline-2,3-dione (DNQX) were obtained from Tocris Bioscience (Ellisville, MO). 6,7,8,9-Tetrahydro5-nitro-1H-benz [g] indole-2,3-dione 3-oxime (NS-102) was obtained from Sigma-Aldrich (St. Louis, MO). All other chemicals were obtained from Fischer Scientific (Hampton, NH) or Sigma-Aldrich.

Pyramidal cells, interneurons expressing EGFP (referred to here as EGFP-expressing SOM interneurons) and non-EGFP interneurons were identified visually in CA1 using infrared differential inference contrast optics and epifluorescent optics on a Nikon (New York, NY) E600FN upright microscope. Interneurons recorded had somata located in s. radiatum. Targeted neurons were patched in the voltage-clamp configuration and recorded at a holding potential of $-60 \mathrm{mV}$ using an Axopatch 200B amplifier ( Molecular Devices, Union City, CA). Patch electrodes (3-4.5 $\mathrm{M} \Omega$ ) were filled with internal solution composed of the following (in mM): 100 Cs-Gluconate, 0.6 EGTA, $5.0 \mathrm{MgCl}_{2}, 10 \mathrm{HEPES}, \mathrm{pH}$ was adjusted to 7.2 with $\mathrm{CsOH}$. The internal solution also contained $10 \mathrm{~mm}$ BAPTA to block interneuron LTP and LTD (Laezza et al., 1999), and to inhibit postsynaptic $\mathrm{Ca}^{2+}$-mediated effects of G-protein coupled receptors and prevent postsynaptic short-term plasticity; QX-314 [N-(2,6dimethylphenylcarbamoylmethyl)triethylammonium chloride] (5 mM) to improve space clamp and reduce nonlinear effects caused by voltagegated channels in dendrites while recording from the soma; $10 \mathrm{~mm}$ ATP to chelate intracellular polyamines and prevent possible postsynaptic short-term plasticity at calcium-permeable AMPA receptors (Bahring et al., 1997; McBain, 1998; Rozov and Burnashev, 1999; Toth et al., 2000). The access resistance and holding current $(<200 \mathrm{pA})$ were monitored continuously. Recordings were rejected if either access resistance or holding current increased $>20 \%$ during the experiment.

EPSCs were recorded in response to extracellular stimulation of Schaffer collateral axons by a bipolar tungsten microelectrode (FHC, Bowdoinham, ME) placed in s. radiatum. Stimulation was generated from a Master-8-cp stimulator (AMPI, Jerusalem, Israel) and applied with a BSI-2 biphasic stimulus isolator (BAK Electronics, Mount Airy, MD). During the recording, the stimulating electrode was positioned and the stimulus strength adjusted $(10-50 \mu \mathrm{A}$ for a $100 \mu$ s pulse) to produce a single-peak EPSC with fixed latency. There were two stimulation patterns used in the experiments: (1) paired-pulse stimulation with different intervals (in ms: 20, 30, 40, 50, 60, 80, 100, 150, 200, and 500), applied in a random sequence and repeated 10 times at $0.1 \mathrm{~Hz}$. The averaged pairedpulse ratio (EPSC $2 / \mathrm{EPSC}_{1}$ ) was calculated after recording; (2) short highfrequency trains (five pulses) at different constant frequencies $(5,10,20$, and $50 \mathrm{~Hz}$ ), repeated 10 times each at $0.033 \mathrm{~Hz}$. The five-pulse ratio (ratio of the response amplitudes of the fifth versus the first pulse $=\mathrm{EPSC}_{5} /$ EPSC $_{1}$ ) was calculated after recording. In each experiment the stimulus amplitude and duration were held constant.

For measurements of the use-dependent block of NDMA responses by $(5 S, 10 R)-(+)$-5-methyl-10,11-dihydro-5H-dibenzo[a,d]cyclohepten-5,10imine maleate (MK-801), APV was omitted from the recording solution and either $10 \mu \mathrm{M}$ DNQX (Fig. 2) or $50 \mu \mathrm{M}$ GYKI 52466 (see Figs. 4G-I, $5 A-C$ ) was added to block AMPA/kainate receptors. The concentrations of calcium $(2.5 \mathrm{~mm})$ and magnesium $(1.3 \mathrm{~mm})$ in the recording solution were not changed. NMDA receptor EPSCs were recorded at $-40 \mathrm{mV}$ in response to stimulation at $0.1 \mathrm{~Hz}$. After a stable baseline was obtained, 40 $\mu \mathrm{M}$ MK-801 was added and stimulation was turned off for $10 \mathrm{~min}$ to allow full wash in and equilibration of MK-801. Stimulation was resumed at $0.1 \mathrm{~Hz}$, and EPSCs were recorded for at least 120 stimuli. Stimulation at $0.1 \mathrm{~Hz}$ was used to avoid causing any short-term plasticity that would alter the release probability. Relative EPSC size was measured by integrating the current in a $40 \mathrm{~ms}$ window around the peak (Huang and Stevens, 1997). A single exponential decay was fit to the EPSC amplitude versus stimulus number in MK-801 to obtain the $\tau$ for the MK801 block.

For experiments measuring miniature EPSCs (mEPSCs), $1 \mu \mathrm{M}$ tetrodotoxin (TTX) was added to block action potentials. mEPSCs were analyzed using custom written software in Visual Basic. Data were recorded for $10-15 \mathrm{~min}$ in each condition; analysis included a minimum of 50 events for each condition for each cell.

Statistical analysis. Data are presented as mean \pm SE. Except where noted, statistical comparisons were made using one-way ANOVA, with $p<0.05$ considered significant. Where noted, statistical comparisons were made using the Student's $t$ test, with $p<0.05$ considered significant.

Mathematical analysis. To investigate possible mechanisms for the differences in short-term plasticity observed in the present study, we use our mechanistic mathematical model of short-term plasticity that describes vesicle release from single synapses (Sun et al., 2005). This model incorporates features of several previous models (Dobrunz and Stevens, 1997; Tsodyks et al., 1998; Dittman et al., 2000; Dobrunz, 2002). Details of mathematical methods are described in the Appendix. All mathematical calculations were performed using Mathematica software (fourth edition, Wolfram Media, Champaign, IL).

\section{Results \\ Excitatory synapses onto SOM interneurons have very large paired-pulse facilitation}

To begin investigating whether the heterogeneity of short-term plasticity at Schaffer collateral synapses onto hippocampal interneurons in s. radiatum is correlated with their neurochemical content, we used the GIN line of transgenic mice to study synapses onto an identified subset of interneurons. GIN mice express EGFP in a subpopulation of GABAergic interneurons that contain the neuropeptide somatostatin (Oliva et al., 2000). Because somatostatin-expressing interneurons are relatively sparse in $\mathrm{s}$. radiatum (Freund and Buzsaki, 1996), using EGFP as a marker allows us to identify them and target them for study. Because the 
EGFP-expressing interneurons are a subset of the somatostatin interneurons (Oliva et al., 2000), we refer to these cells here as EGFP-expressing SOM interneurons. Using whole-cell voltage clamp recordings, we compared short-term plasticity of Schaffer collateral synapses onto EGFP-expressing SOM interneurons in s. radiatum to short-term plasticity of Schaffer collateral synapses onto non-EGFP interneurons in s. radiatum and onto CA1 pyramidal cells in acute hippocampal slices from juvenile GIN mice. To enable study of short-term plasticity of excitatory synapses in isolation, inhibitory synapses and long-term plasticity were pharmacologically blocked.

Unlike synapses onto other interneurons, Schaffer collateral excitatory synapses onto EGFP-expressing SOM interneurons showed very large paired-pulse facilitation. Figure $1 A$ shows example average traces of EPSCs in response to paired-pulse stimulation at $50 \mathrm{~ms}$ interval for an EGFP-expressing SOM interneuron (green), a non-EGFP interneuron (black), and a pyramidal cell (red). In agreement with our previous observations from rat hippocampal slices (Sun et al., 2005), synapses onto non-EGFP interneurons in the GIN mice had very little paired-pulse facilitation, and some had small paired-pulse depression. In contrast, synapses onto EGFP-expressing SOM interneurons had very large paired-pulse facilitation that was even larger than the paired-pulse facilitation onto CA1 pyramidal cells. As seen in the group summary in Figure $1 B$, the paired-pulse ratios were significantly different for the three groups for intervals of $20-200 \mathrm{~ms}$ ( $p<0.05$ ); by $500 \mathrm{~ms}$, paired-pulse plasticity had largely disappeared. There was some trial to trial variation in the size of the responses; example raw traces are shown in supplemental Figure $1 A-C$ (available at www.jneurosci.org as supplemental material). The cell to cell variation in the amount of paired-pulse facilitation was largest for the synapses onto the EGFP-expressing SOM interneurons, as illustrated in supplemental Figure $1 D-E$ (available at www.jneurosci.org as supplemental material). However, all EGFP-expressing SOM interneurons tested had more facilitation than any of the other interneurons tested that lacked the marker EGFP.

\section{Frequency-facilitation is also large at synapses onto EGFP-expressing SOM interneurons}

The differences between Schaffer collateral synapses onto EGFPexpressing SOM interneurons versus Schaffer collateral synapses onto non-EGFP interneurons and pyramidal cells are even greater in response to short high-frequency trains. Figure $1 C$ shows example traces of the responses to five-pulse trains at 20 $\mathrm{Hz}$. Whereas the synaptic response of the pyramidal cell (red) showed robust facilitation during the train, the response of the EGFP-expressing SOM interneuron (green) showed extremely large facilitation that accumulated during the train. In contrast, synapses onto the non-EGFP interneuron (black) showed shortterm depression during the train. The responses were quantified by the five pulse ratio $\left(\mathrm{EPSC}_{5} / \mathrm{EPSC}_{1}\right.$ ) (Fig. $1 \mathrm{D}$ ), which shows that this large facilitation was observed at synapses onto EGFPexpressing SOM interneurons during five-pulse trains over a range of frequencies from $5-50 \mathrm{~Hz}$. The responses of synapses onto EGFP-expressing SOM interneurons showed significantly more facilitation than synapses onto pyramidal cells and nonEGFP interneurons $(p<0.05)$.

\section{Warmer temperature does not significantly alter short-term facilitation}

The recordings in Figure $1 A-D$ were done at room temperature $\left(24-25^{\circ} \mathrm{C}\right)$. Because some forms of short-term plasticity may be
A

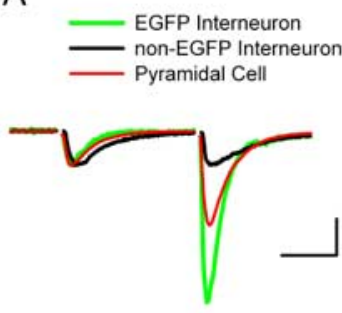

C

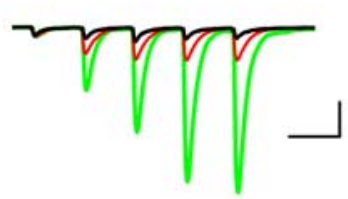

E

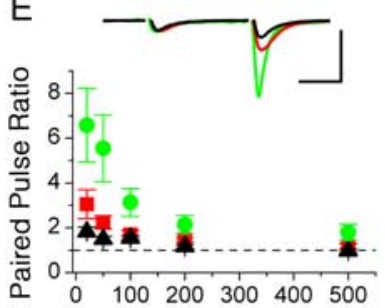

Paired Pulse Interval (ms)
B

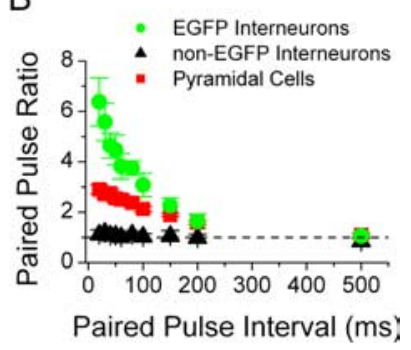

D

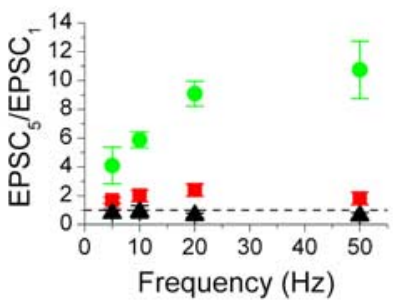

$\mathrm{F}$

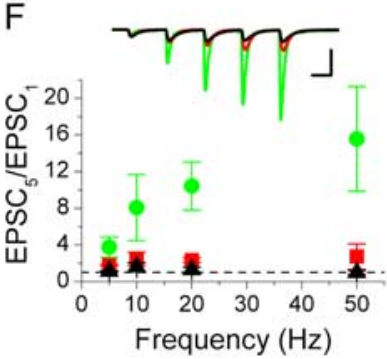

Figure 1. Excitatory synapses onto EGFP-expressing SOM interneurons have very large short-term facilitation. $A$, Examples of EPSCs recorded from an s. radiatum EGFP-expressing SOM interneuron (green), CA1 pyramidal cell (red), and s. radiatum non-EGFP interneuron (black) in response to paired-pulse stimulation ( $50 \mathrm{~ms}$ interval) of Schaffer collateral axons. Each trace is the average of 10 responses. Traces are shown scaled so that the first EPSCs are the same size. Calibration: $20 \mathrm{~ms}, 180 \mathrm{pA}$ (pyramidal cell), $50 \mathrm{pA}$ (non-EGFP interneuron), $46 \mathrm{pA}$ (EGFP-expressing SOM interneuron). $\boldsymbol{B}$, Group results (mean $\pm \mathrm{SE}$ ) for paired-pulse ratios versus interval from EGFP-expressing SOM interneurons (green circles; $n=11$ ), pyramidal cells (red squares; $n=7$ ), and non-EGFP interneurons (black triangles; $n=9$ ) show significant differences for intervals of $20-200 \mathrm{~ms}(p<0.05)$. C, Examples of EPSCs recorded from an s. radiatum EGFP-expressing SOM interneuron (green), CA1 pyramidal cell (red), and s. radiatum non-EGFP interneuron (black) in response to five-pulse stimulation $(20 \mathrm{~Hz})$ of Schaffer collateral axons. Each trace is the average of 10 responses. Traces are shown scaled so that the first EPSCS are the same size. Calibration: $50 \mathrm{~ms}, 500 \mathrm{pA}$ (pyramidal cell), $134 \mathrm{pA}$ (non-EGFP interneuron), 121 pA (EGFP-expressing SOM interneuron). $\boldsymbol{D}$, Group results for five-pulse ratios versus frequency from EGFP-expressing SOM interneurons (green circles; $n=5$ ), pyramidal cells (red squares; $n=4$ ), and non-EGFP interneurons (black triangles; $n=4$ ) show significant differences for frequencies of $5-50 \mathrm{~Hz}(p<0.05)$. $\boldsymbol{E}, \boldsymbol{F}$, Short-term facilitation is also large at synapses onto EGFP-expressing SOM interneurons at warmer temperature. $\boldsymbol{E}$, Group results for paired-pulse ratios versus intervals recorded at $33^{\circ} \mathrm{C}$ show greater facilitation at synapses onto EGFP-expressing SOM interneurons (green circles; $n=5$ ) compared with pyramidal cells (red squares; $n=4)$ and non-EGFP interneurons (black triangles; $n=5)(p<0.05)$. Inset, Example traces for $50 \mathrm{~ms}$ interval. Traces are shown scaled so that the first EPSCs are the same size. Calibration: 20 ms, 300 pA (pyramidal cell), 200 pA (non-EGFP interneuron), 44 pA (EGFPexpressing SOM interneuron). $\boldsymbol{F}$, Group results for five-pulse ratios versus frequency recorded at $33^{\circ} \mathrm{C}$ show greater facilitation at synapses onto EGFP-expressing SOM interneurons (green circles; $n=5$ ) as compared with pyramidal cells (red squares; $n=4$ ) and non-EGFP interneurons (black triangles; $n=5)(p<0.05)$. Inset, Example traces at $20 \mathrm{~Hz}$. Traces are shown scaled so that the first EPSCs are the same size. Calibration: $50 \mathrm{~ms}, 275 \mathrm{pA}$ (pyramidal cell), $175 \mathrm{pA}$ (non-EGFP interneuron), $95 \mathrm{pA}$ (EGFP-expressing SOM interneuron).

temperature dependent (Hardingham and Larkman, 1998; Klyachko and Stevens, 2006), we also examined the responses at warmer temperatures. Figure 1, $E$ and $F$, shows the results from recordings at $33^{\circ} \mathrm{C}$, which verified that Schaffer collateral syn- 
apses onto EGFP-expressing SOM interneurons also have large facilitation at this near-physiological temperature. In fact, although there was a trend toward an increase in facilitation at the warmer temperature, the paired-pulse ratios and five-pulse ratios were not significantly different between the room temperature and $33^{\circ} \mathrm{C}$ recordings. Therefore, short-term facilitation at these synapses does not appear to be very sensitive to temperature changes in this range. This is consistent with the observation that the release probability of Schaffer collateral synapses onto CA1 pyramidal cells does not significantly change between room temperature and near-physiological temperature (Allen and Stevens, 1994), although synapses on hippocampal neurons in culture appear to be more sensitive to temperature (Pyott and Rosenmund, 2002; Micheva and Smith, 2005). Because it allows us to compare with our previous data, and because it is easier to maintain slice health for longer periods at room temperature, we therefore returned to room temperature recordings for the remainder of this study.

\section{Synapses onto EGFP-expressing SOM interneurons have a low initial release probability}

In hippocampal slices from rat, we have shown previously that Schaffer collateral excitatory synapses onto s. radiatum interneurons have a higher initial release probability than Schaffer collateral synapses onto CA1 pyramidal cells (Sun et al., 2005). Because the amount of paired-pulse facilitation is often inversely related to the initial release probability of synapses (e.g., Dobrunz and Stevens, 1997; for review, see Zucker and Regehr, 2002), the extremely large facilitation of Schaffer collateral synapses onto the EGFP-expressing SOM interneurons in GIN mice suggests that they instead have a very low initial release probability. We tested this using the rate of use-dependent block of NMDA receptors by the open-channel blocker MK-801 (Huang and Stevens, 1997), an established method for showing differences in the average release probability (e.g., Castro-Alamancos and Connors, 1997). We compared the rate of block of NMDA EPSCs by MK-801 at synapses onto EGFP-expressing SOM interneurons in s. radiatum versus non-EGFP interneurons and pyramidal cells, using single pulse stimulation at $0.1 \mathrm{~Hz}$ to avoid short-term plasticity. Figure $2 \mathrm{~A}$ shows that the MK-801 blocking curves measured at synapses onto the three cell types are different. The rate of block of the NMDA synaptic currents by MK- 801 is fastest at synapses onto non-EGFP interneurons, intermediate at synapses onto pyramidal cells, and slowest at synapses onto the EGFP-expressing SOM interneurons. The time constant of the decay (measured in number of stimuli) shows statistically significant differences between all three cell types (Fig. $2 B)(p<0.05)$. This shows that synapses onto non-EGFP interneurons in s. radiatum have a higher average initial release probability than synapses onto CA1 pyramidal cells in GIN mice, in agreement with our results from rat slices (Sun et al., 2005). However, the slow rate of block for synapses onto EGFP-expressing SOM interneurons suggests that they have a very low initial release probability, which is lower than the release probability at synapses onto pyramidal cells.

Although the MK-801 method is a widely used technique to test for differences in release probability, the rate of MK-801 block is also determined by the open probability of NMDA receptors and the fraction of open receptors that are blocked by a given concentration of MK-801 (Huang and Stevens, 1997). If there is a difference in NMDA receptor subunit composition in the different cell types, and if some NMDA receptors are more easily blocked by MK-801 (Lei and McBain, 2002) (but see Chen et al., 1999; Chavis and Westbrook, 2001), this could also con-

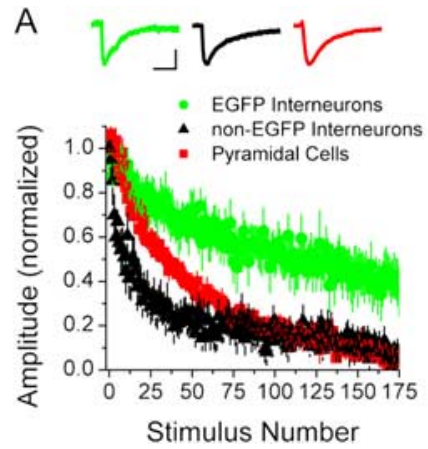

B

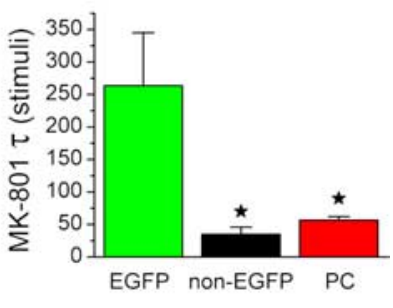

Figure 2. Synapses onto EGFP-expressing SOM interneurons have a low initial release probability. $\boldsymbol{A}$, Rate of block of NMDA EPSCs by $40 \mu \mathrm{M}$ MK-801 is very slow for EGFP-expressing SOM interneurons (green circles; $n=5$ ), indicating a low release probability. Blocking rate is faster for synapses onto pyramidal cells (red squares; $n=6$ ), indicating a higher release probability, and even faster for synapses onto non-EGFP interneurons (black triangles; $n=9$ ), indicating that their release probability is even higher. Inset, Example NMDA EPSCs from EGFP-expressing SOM interneuron (left; green), non-EGFP interneuron (center; black), and pyramidal cell (right; red). Calibration: $50 \mathrm{~ms}, 16 \mathrm{pA}$ (EGFP-expressing SOM interneuron), $28 \mathrm{pA}$ (non-EGFP interneuron), $40 \mathrm{pA}$ (pyramidal cell). $\boldsymbol{B}$, Average MK-801 decay constant ( $\tau$, in number of stimuli) is statistically different between EGFP-expressing SOM interneurons $(\tau=263.4 \pm 81.5)$, nonEGFP interneurons $(\tau=34.8 \pm 11.3)$, and pyramidal cells $(\tau=56.6 \pm 5.3) .{ }^{*} p<0.05$.

tribute to the observed difference in the MK- 801 blocking curves. Target cell-specific differences in NMDA receptor subunits have been found at mossy fiber synapses onto CA3 interneurons in hippocampus (Lei and McBain, 2002), and CA1 pyramidal cells and interneurons may also have differences in NMDA receptor subunit composition (Standaert et al., 1996; Avignone et al., 2005). If EGFP-expressing SOM interneurons have NMDA receptors that are less susceptible to MK-801 block, this could also contribute to their slower rate of MK-801 block. However, the time course of the NMDA EPSCs was similar for all three cell types (Fig. 2A, inset). The decay time constants of the NMDA EPSCs were not statistically different between the three groups $(\tau=29.8 \pm 11.6 \mathrm{~ms}$ for EGFP-expressing SOM interneurons; $\tau=$ $77.8 \pm 17.9 \mathrm{~ms}$ for non-EGFP interneurons; $\tau=56.7 \pm 10.0 \mathrm{~ms}$ for pyramidal cells; $p>0.05)$. Because differences in the NMDA receptor subunit composition result in changes in the NMDA EPSC time course (Flint et al., 1997; Stocca and Vicini, 1998; Lei and McBain, 2002), this suggests that the NMDA receptor subunit composition is similar between the three cell types. Any contribution of NMDA receptor differences to the slower block by MK- 801 is likely to be small, and not enough to account for the large difference in blocking rate.

The fact that the decay constant is nearly eight times slower than that for non-EGFP interneurons suggests that EGFPexpressing SOM interneurons do have a low release probability. The large facilitation at these synapses is likely to arise at least in part from their low initial release probability.

\section{Model predicts that low release probability alone cannot account for all of the large short-term facilitation at synapses onto EGFP-expressing SOM interneurons}

Our experimental data show that Schaffer collateral synapses onto EGFP-expressing SOM interneurons have large short-term facilitation and a low initial release probability. To try to test whether a low initial release probability could be sufficient to quantitatively account for the magnitude of the large pairedpulse and five-pulse facilitation observed, we used a mechanistic mathematical model of short-term plasticity that we developed in a previous paper (Sun et al., 2005). Our model is mechanistic, in 

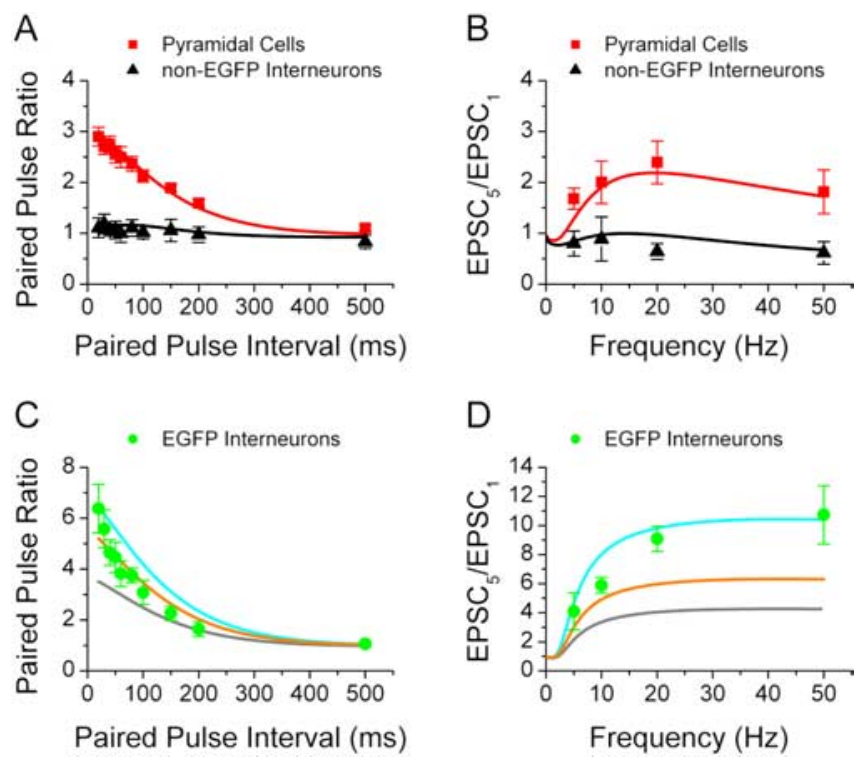

Figure 3. Model fits data from pyramidal cells and non-EGFP interneurons, but not EGFPexpressing SOM interneurons. $\boldsymbol{A}, \boldsymbol{B}$, Mathematical model of short-term plasticity (solid lines) provides good fit to both paired-pulse $(\boldsymbol{A})$ and five-pulse $(\boldsymbol{B})$ data for synapses onto pyramidal cells (red squares) and non-EGFP interneurons (black triangles). All model parameters are the same (Table 2) except for a smaller initial readily releasable vesicle pool size $\left(n_{T}\right)$ and smaller initial release probability per vesicle $\left(\alpha_{1}\right)$ at synapses onto pyramidal cells (Table 1), resulting in a lower initial release probability $\left(P_{1}=0.17\right.$ for pyramidal cells; $P_{1}=0.52$ for non-EGFP interneurons). $C, D$, For synapses onto EGFP-expressing SOM interneurons, model simulations that only changed the initial release probability were unable to fit both the paired-pulse $(\boldsymbol{C})$ and five-pulse data $(\boldsymbol{D})$ using the same parameters. Figures show example model simulations for $P_{1}=0.073$ [top curves (cyan), $\alpha_{1}=0.015$ and $n_{T}=5$ ], $P_{1}=0.096$ [middle curves (orange), $\alpha_{1}=0.02$ and $n_{T}=5$ ], and $P_{1}=0.14$ [lower curves (gray), $\alpha_{1}=0.03$ and $n_{T}=5$ ].

that we attempt to include variables with physiological counterparts, and it incorporates features of several previous models (Abbott et al., 1997; Dobrunz and Stevens, 1997; Tsodyks et al., 1998; Dittman et al., 2000; Dobrunz, 2002). In our model, synapses cycle between three states: "release-ready," "releasing," and "refractory." Neurotransmitter release can only occur from synapses in the release-ready state, which release a single vesicle per active synapse with an average release probability $P(t) . P(t)$ depends on the number of readily releasable vesicles and on the release probability per vesicle, both of which are modified by the pattern of activity. Facilitation occurs through a calciumdependent increase in the release probability per vesicle. Depression results from depletion of the readily releasable vesicle pool and from synapses becoming refractory after release. Details of the model are in the Appendix and in our previous paper (Sun et al., 2005).

We showed previously that our mathematical model was able to account for all of the differences in short-term plasticity between Schaffer collateral synapses onto s. radiatum interneurons versus CA1 pyramidal cells in hippocampal slices from rat by a higher initial release probability at synapses onto interneurons, caused by larger values of both the initial readily releasable vesicle pool size and the initial release probability per vesicle (Sun et al., 2005). We next applied the model to our short-term plasticity data from the GIN mice. For synapses onto pyramidal cells and non-EGFP interneurons, the model was able to simultaneously fit the paired-pulse and five-pulse data (Fig. $3 A, B$ ) using the same model parameters for both types of stimulation (Tables 1 , 2 ). For these two groups, the results from GIN mice were very similar to those from rat, in that the model predicted that the differences between these synapses resulted from a higher initial readily releasable vesicle pool size and a higher initial release probability per vesicle at the synapses onto non-EGFP interneurons, resulting in a higher initial release probability for interneuron inputs $\left(P_{1}=0.52\right)$ compared with pyramidal cell inputs $\left(P_{1}=0.17\right)$.

In contrast, the model was not able to simultaneously fit the paired-pulse and five-pulse data for the EGFP-expressing SOM interneuron synapses by only changing release probability, with any combination of changes in readily releasable pool size and release probability per vesicle that we tested. Figure $3, C$ and $D$, shows three examples of simulations of the paired-pulse data (Fig. 3C) and five-pulse data (Fig. 3D) for the EGFP-expressing SOM interneurons, where the initial release probability varies $\left[P_{1}\right.$ $=0.073$ (top curves, cyan), $P_{1}=0.096$ (middle curves, orange), and $P_{1}=0.14$ (bottom curves, gray)]. No value of $P_{1}$ fit both the peak and the shape of the paired-pulse data (Fig. 3C), and the parameters that provided the closest fit $\left(P_{1}=0.096\right)$ resulted in a very poor fit to the five-pulse data (Fig. $3 D$ ). The inability of the model to fit the data with only a change in release probability led us to believe that another mechanism may also contribute to the large paired-pulse and five-pulse facilitation of Schaffer collateral synapses onto EGFP-expressing SOM interneurons in s. radiatum, a prediction which we confirmed by additional experiments.

\section{Presynaptic kainate receptors contribute to large facilitation at synapses onto EGFP-expressing SOM interneurons}

Kainate receptors have been shown to act as presynaptic autoreceptors that contribute to the large short-term facilitation observed at mossy fiber synapses in the CA3 region of hippocampus (Contractor et al., 2001; Lauri et al., 2001; Schmitz et al., 2001). However, previous studies have shown no such role for kainate receptors at Schaffer collateral synapses onto CA1 pyramidal cells, but instead found that activation of kainate receptors by exogenous agonist depresses glutamate release (Kamiya and Ozawa, 1998; Frerking et al., 2001). We tested whether kainate receptors contribute to the large short-term facilitation seen at Schaffer collateral synapses onto EGFP-expressing SOM interneurons by applying the kainate receptor antagonist NS-102, which blocks kainate receptors containing the GluR6 subunit (for review, see Chittajallu et al., 1999). Figure $4 A$ shows examples of paired-pulse EPSCs (40 ms interval) recorded in an EGFPexpressing SOM interneuron before (green trace) and during (magenta trace) the application of NS-102 $(20 \mu \mathrm{M})$. The kainate receptor antagonist caused a significant reduction in the amount of paired-pulse facilitation, although the remaining facilitation was still large. Figure $4 B$ shows a summary of the results (mean \pm SE) of paired-pulse ratio for EGFP-expressing SOM interneurons with NS-102 versus control. A paired two sample $t$ test showed that there were significant differences in the paired-pulse ratio before and during NS-102 administration at 20-60 ms pairedpulse intervals $(p<0.05)$.

NS-102 also caused a small decrease in the size of the first EPSC $(29.7 \pm 3.6 \%$; $p<0.05)$, which was partially reversed after washout. NS-102 has been reported to be highly selective for kainate receptors versus AMPA receptors (Wilding and Huettner, 1996); however, one study in cultured hippocampal neurons reported similar potency for AMPA versus kainate receptors (Paternain et al., 1996). It is possible that the decrease in the first EPSC size represents a weak antagonism of AMPA receptors (Paternain et al., 1996), which should not result in any change in short-term facilitation and therefore would not influence our 
Table 1. Values of the model parameters that were adjusted to fit the experimental data

\begin{tabular}{|c|c|c|c|c|c|c|}
\hline Cell group & Stimulation object & $\begin{array}{l}\text { Initial release } \\
\text { probability per } \\
\text { vesicle } \alpha_{1}\end{array}$ & $\begin{array}{l}\text { Initial readily } \\
\text { releasable pool } \\
\text { size } n_{T}\end{array}$ & $\begin{array}{l}\text { Initial release } \\
\text { probability } P_{1}\end{array}$ & $\begin{array}{l}\text { Increment in }\left(a X_{K A R}\right. \\
\text { after a stimulus, } \\
\Delta_{K A R} \text { (normalized) }\end{array}$ & $\begin{array}{l}\text { Decay constant of } \\
\mathrm{CaX}_{K A R^{\prime}} \tau_{K A R} \text { (ms) }\end{array}$ \\
\hline \multirow[t]{2}{*}{ Pyramidal cells } & Paired-pulse ratio versus interval & 0.037 & 5.0 & 0.17 & 0 & NA \\
\hline & Five-pulse ratio versus frequency & 0.037 & 5.0 & 0.17 & 0 & NA \\
\hline \multirow[t]{2}{*}{ Non-EGFP interneurons } & Paired-pulse ratio versus interval & 0.090 & 8.0 & 0.52 & 0 & NA \\
\hline & Five-pulse ratio versus frequency & 0.090 & 8.0 & 0.52 & 0 & NA \\
\hline \multirow[t]{2}{*}{ EGFP-expressing SOM interneurons control } & Paired-pulse ratio versus interval & 0.025 & 5.0 & 0.12 & 5 & 25 \\
\hline & Five-pulse ratio versus frequency & 0.025 & 5.0 & 0.12 & 5 & 25 \\
\hline \multirow[t]{2}{*}{ EGFP-expressing SOM interneurons in NS-102 } & Paired-pulse ratio versus interval & 0.025 & 5.0 & 0.12 & 0 & NA \\
\hline & Five-pulse ratio versus frequency & 0.025 & 5.0 & 0.12 & 0 & NA \\
\hline
\end{tabular}

All parameters are independent variables except $P_{1}$, which was calculated from the values of $\alpha_{1}$ and $n_{T}$ (for model description, see Appendix).

Table 2. Parameters held constant in the model simulations for all cell types and stimulus protocols

\begin{tabular}{llcc}
\hline Symbol & Definition & Value & Unit \\
\hline$\tau_{i n}$ & Time constant for entry into refractory state & $3^{a}$ & $\mathrm{~ms}$ \\
$k_{0}$ & Baseline recovery rate from the refractory state & $2^{a}$ & $\mathrm{~s}^{-1}$ \\
$k_{\max }$ & Maximum recovery rate from the refractory state & $30^{a}$ & $\mathrm{~s}^{-1}$ \\
$\Delta_{D}$ & Incremental increase in CaX after a stimulus & $4^{a}$ & (normalized) \\
$K_{D}$ & Dissociation constant of $C a X_{D}$ & $2^{a}$ & $\mathrm{~N} / \mathrm{A}$ \\
$\tau_{D}$ & Decay time constant of $C a X_{D}$ after a stimulus & $15^{a}$ & $\mathrm{~ms}$ \\
$\Delta_{F}$ & Incremental increase in CaX after a stimulus & $1^{a}$ & (normalized) \\
$K_{F}$ & Dissociation constant of $C a X_{F}$ & 5 & $\mathrm{~N} / \mathrm{A}$ \\
$\tau_{F}$ & Decay constant of $C a X_{F}$ & 60 & $\mathrm{~ms}$ \\
$R$ & Refilling rate of readily releasable vesicle pool & $0.1^{a}$ & $\mathrm{~s}$ \\
\hline
\end{tabular}

N/A, Not applicable.

${ }^{a}$ Parameters are the same as those used in our previous paper, Sun et al. 2005.

results. Alternatively, it could reflect the block of postsynaptic kainate receptors that contribute to the EPSC, because postsynaptic kainate receptors containing GluR6 are found in CA1 interneurons (Mulle et al., 2000; Christensen et al., 2004). However, their contribution to the EPSC peak is small (Frerking et al., 1998), and blocking them should have no effect on short-term facilitation. Finally, the reduction in the first EPSC by NS-102 could be caused by the block of presynaptic facilitatory kainate receptors that were tonically activated by endogenous glutamate. However, that would cause an increase in paired-pulse facilitation, rather than the decrease in facilitation that we observed. The reduction of short-term facilitation by NS-102 at synapses onto EGFP-expressing SOM interneurons is therefore most likely caused by block of the effects of synaptically released glutamate, rather than an indirect effect of an increase in the initial release probability.

We next investigated the contribution of kainate receptors on the extremely large frequency facilitation observed at synapses onto EGFP-expressing SOM interneurons during short trains. We compared the amount of facilitation evoked by five-pulse trains at different frequencies $(5,10,20$, and $50 \mathrm{~Hz})$ before and during application of NS-102 (Fig. 4C). NS-102 decreased the five-pulse ratio at 20 and $50 \mathrm{~Hz}(n=5$; paired Student's $t$ test, $p<$ $0.05)$, but there was no significant change at 5 and $10 \mathrm{~Hz}(p>$ $0.05)$. The effect of NS-102 on paired-pulse and frequency facilitation demonstrates that the activation of presynaptic kainate receptors contributes to the large facilitation observed in excitatory synapses onto EGFP-expressing SOM interneurons in CA1 s. radiatum during high-frequency stimulation but not during lower-frequency stimulation.

To investigate if the role of presynaptic GluR6 kainate receptors is unique for short-term facilitation observed in EGFPexpressing SOM interneurons, we next tested the effects of the kainate receptor antagonist NS-102 on short-term plasticity in non-EGFP interneurons and pyramidal cells. Figure $4 D$ shows examples of paired-pulse EPSCs (40 ms interval) recorded in a non-EGFP interneuron before (black trace) and during (gray trace) the application of NS-102. NS-102 caused a small decrease in the size of the EPSC for both pulses, with no change in the paired-pulse ratio. NS-102 had no effect on the paired-pulse ratio for any of the non-EGFP interneurons tested; the results are summarized in Figure $4 E$ ( $n=5$; paired Student's $t$ test, $p>0.05$ ). Similarly, NS-102 had no effect on the five-pulse ratio in non-EGFP interneurons during short trains (Fig. $4 F)(n=5$; paired Student's $t$ test, $p>0.05)$. NS-102 also had no effect on the paired-pulse ratio or five-pulse ratio for Schaffer collateral synapses onto pyramidal cells $(n=5$; paired Student's $t$ test, $p>0.05$ ) (data not shown). NS-102 caused a decrease in the size of the first EPSC in both non-EGFP interneurons $(27.6+4.2 \% ; n=5$, paired Student's $t$ test, $p<0.05)$ and pyramidal cells $(22.2 \pm 5.5 \% ; n=5$, paired Student's $t$ test, $p<$ $0.05)$, consistent with it also acting as a weak AMPA receptor antagonist. These results show that GluR6-containing kainate receptors are not involved in short-term plasticity observed in non-EGFP interneurons and pyramidal cells, and therefore this mechanism is unique to the EGFP-expressing SOM interneurons.

To further support our finding that kainate receptors contribute to short-term facilitation at Schaffer collateral synapses onto EGFP-expressing SOM interneurons, we next verified that blocking kainate receptors with a more general kainate receptor antagonist also reduces paired-pulse facilitation. To do this, we first recorded paired-pulse responses of NMDA receptor mediated EPSCs in the presence of the selective AMPA receptor blocker GYKI $52466(50 \mu \mathrm{M})$, and compared the amount of facilitation in control and with kainate receptors blocked by DNQX (Schmitz et al., 2001). For EGFP-expressing SOM interneurons, application of $10 \mu \mathrm{M}$ DNQX caused a reduction in the paired-pulse ratio of the NMDA EPSC for intervals up to $100 \mathrm{~ms}$ (Fig. $4 G)(n=5$; paired Student's $t$ test, $p<0.05$ ), again indicating that the effect of kainate receptor activation was rapid and short lasting. The amplitude of the first EPSC was also slightly reduced $(37.1 \pm 9 \%$; paired Student's $t$ test, $p<0.05)$. The effect was also reversible; after DNQX washout, both the paired-pulse ratio and the first EPSC amplitude returned to the control 
levels $(p>0.05)$. In the controls, the NMDA paired-pulse ratio was slightly smaller than the AMPA paired pulse ratio at short intervals. This may reflect partial block of the kainate receptors by the GYKI 52466, which, although AMPA preferring, is also a weak antagonist of kainate receptors (Paternain et al., 1995). The kainate receptors on EGFPexpressing SOM interneurons are at most partially blocked by $50 \mu \mathrm{M}$ GYKI 52466, however, because addition of DNQX caused a significant reduction of the NMDA paired-pulse ratio at short intervals. The effect of kainate receptor activation on paired-pulse facilitation effect was specific to EGFP-expressing SOM interneurons, because no change in paired-pulse facilitation of NMDA responses was observed for either nonEGFP interneurons (Fig. $4 H)(n=6$; paired Student's $t$ test, $p>0.05)$ or pyramidal cells (Fig. $4 I)(n=5$; paired Student's $t$ test, $p>0.05)$.

Together, our results show that the large facilitation at synapses onto EGFPexpressing SOM interneurons in s. radiatum is attributable in part to activation of kainate receptors, including kainate receptors containing the GluR6 subunit. These receptors are activated by synaptically released glutamate, and their effect is to increase the size of the EPSC on subsequent stimuli, thereby increasing shortterm facilitation.

\section{Activating presynaptic kainate receptors increases release probability at synapses onto EGFP-expressing SOM interneurons}

Because nearly all mechanisms of shortterm facilitation are presynaptic (for review, see Zucker and Regehr, 2002), the simplest explanation for the facilitatory effect of the kainate receptors at synapses onto EGFP-expressing SOM interneurons is that they are located presynaptically. When activated by synaptically released glutamate from the first pulse, they cause an increase in the probability of glutamate release on subsequent pulses. To test this, we next determined whether activation of kainate receptors by bath application of exogenous agonist causes an increase in the probability of glutamate release. Because there are no GluR6 selective kainate receptor agonists available, we used $100 \mathrm{~nm}$ kainate, a concentration that has been shown to activate the high affinity kainate receptors that facilitate synaptic transmission at mossy fiber synapses (Schmitz et al., 2001; Ji and Staubli, 2002), but have no effect at Schaffer collateral synapses onto CA1 pyramidal cells (Ji and Staubli, 2002). To directly show that kainate receptor activation is increasing glutamate release rather than increasing the EPSCs postsynaptically, we compared the rate of block of the NMDA EPSC by MK-801 in the presence of 100 nM kainate versus control. For these experiments, we used the selective antago-
B

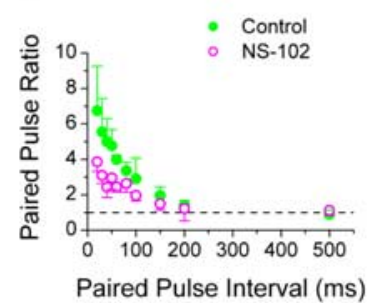

E

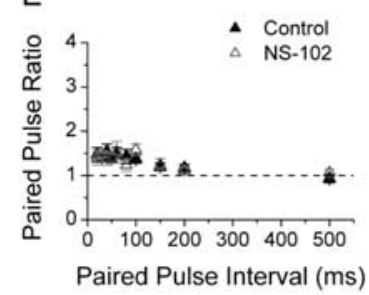

$\mathrm{H}$

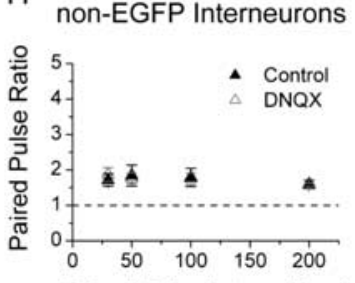

Paired Pulse Interval (ms)
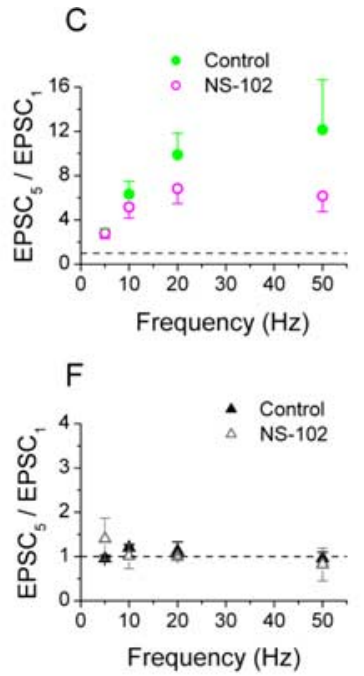

I

Pyramidal Cells

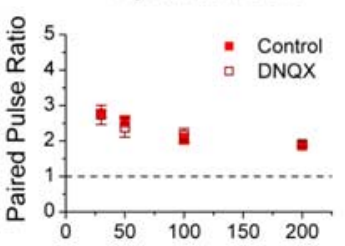

Paired Pulse Interval (ms)
Figure 4. Kainate receptor antagonist reduces facilitation at synapses onto EGFP-expressing SOM interneurons. $A$, Examples of EPSCs recorded from an s. radiatum EGFP-expressing SOM interneuron before (green) and during (magenta) application of the versus interval from EGFP-expressing SOM interneurons before (solid green circles) and during application of NS-102 (open magenta circles) ( $n=6$ ). NS-102 caused a significant decrease in paired-pulse facilitation for intervals from 20 to $60 \mathrm{~ms}$ (paired circles) and during application of NS-102 (open magenta circles) $(n=10)$. NS-102 causes a significant reduction in the five-pulse Calibration: $25 \mathrm{~ms}, 120 \mathrm{pA}$. E, Group results for paired-pulse ratios versus interval from non-EGFP interneurons before (solid black triangles) and during application of NS-102 (open gray triangles) $(n=5)$. NS-102 had no effect on the paired-pulse ratio in non-EGFP interneurons (paired $t$ test, $p>0.05$ ). $\boldsymbol{F}$, Group results for five-pulse ratios versus frequency from non-EGFP interneurons before (solid black triangles) and during application of NS-102 (open gray triangles) $(n=5)$. NS-102 had no effect on the with GYKI $52466(50 \mu \mathrm{M})$. The non-selective AMPA/kainate antagonist DNQX (10 $\mu \mathrm{M})$ was used to block kainate receptors. Filled ( 25,50 , and 100 ms interpulse intervals (paired $t$ test $p<0.05$ ). $H, I$, Group results show that there was no effect of DNQX on the paired-pulse ratio for either non-EGFP interneurons $(\boldsymbol{H} ; n=6)$ or pyramidal cells $(\boldsymbol{l} ; n=5)$ (paired $t$ test, $p>0.05$ ).

nist GYKI $52466(50 \mu \mathrm{M})$ to block AMPA receptors, rather than DNQX, to avoid blocking kainate receptors. The MK-801 blocking functions measured with GYKI 52466 are not different from those in Figure 2 measured with DNQX $(\tau=224.8 \pm 74.0$ vs $263.4 \pm 81.5$; Student's $t$ test, $p>0.05$ ), indicating that the kainate receptors are not tonically activated by ambient glutamate levels. As predicted, activating kainate receptors by bath application of kainate caused an increase in the rate of block by MK-801 of NMDA EPSCs in EGFP-expressing SOM interneurons (Fig. $5 A)(\tau=224.8 \pm 74.0$ vs $10.7 \pm 3.0$; Student's $t$ test, $p<0.05$; $n=$ $5)$. Because NMDA receptors are insensitive to kainate (Hollmann and Heinemann, 1994), this result directly shows that activation of kainate receptors causes an increase in the probability of glutamate release. The effect was selective for EGFP-expressing SOM interneurons, in that addition of $100 \mathrm{~nm}$ kainate had no 

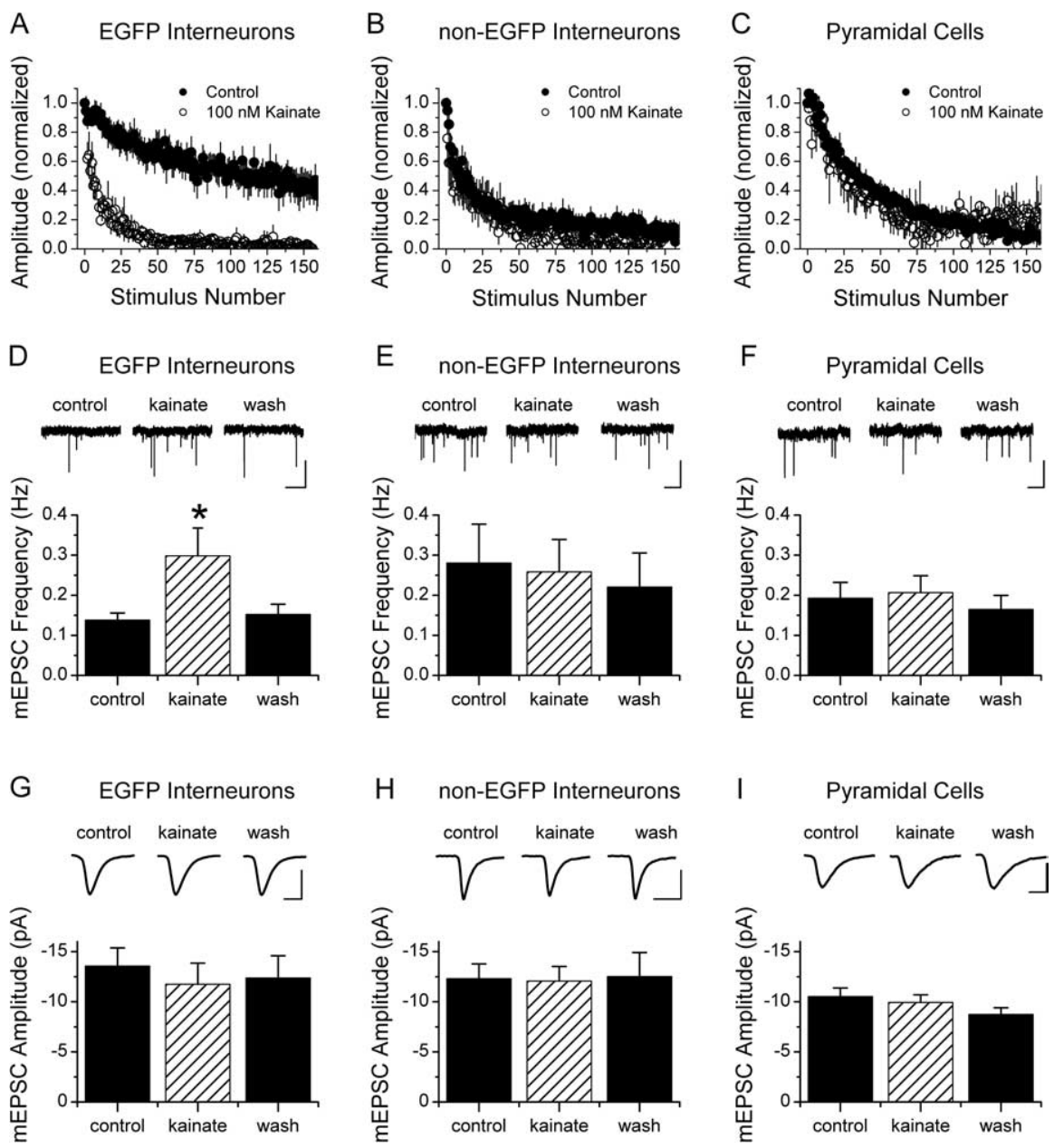

Figure 5. Activation of presynaptic kainate receptors increases the release probability at synapses onto EGFP-expressing SOM interneurons. $\boldsymbol{A}$, Bath application of $100 \mathrm{~nm}$ kainate (open circles) increases the rate of block of NMDA EPSC by $40 \mu \mathrm{m}$ MK-801 for EGFP-expressing SOM interneurons compared with control (closed circles; $n=5 ; \tau_{\text {control }}=224.8 \pm 74.0 \mathrm{vs} \tau_{\text {kainate }}=10.7 \pm$ 3.0; $t$ test, $p<0.05$ ), indicating an increase in the release probability. $\boldsymbol{B}, \boldsymbol{C}$, Kainate had no effect on the MK-801 blocking rate at synapses onto non-EGFP interneurons $\left(\boldsymbol{B} ; n=9 ; \tau_{\text {control }}=25.5 \pm 5.0 \mathrm{vs} \tau_{\text {kainate }}=27.5 \pm 9.1 ; t\right.$ test, $\left.p>0.05\right)$ or pyramidal cells $\left(\boldsymbol{C} ; n=6 ; \tau_{\text {control }}=52.0 \pm 4.7\right.$ vs $\tau_{\text {kainate }}=63.6 \pm 10.7 ; t$ test, $\left.p>0.05\right)$. D, Bath application of 100 nm kainate increases the frequency of $m E P S C s$ recorded in EGFP-expressing SOM interneurons; the effect is reversed by wash out. Top panels show example traces from an EGFP-expressing SOM interneuron recorded during control, kainate, and wash. Bottom panel shows the group results showing an increase in the mEPSC frequency during kainate application $\left(n=8\right.$; ${ }^{*}$ statistically significant, $\left.p<0.05\right)$. $\boldsymbol{E}, \boldsymbol{F}$, Kainate had no effect on the mEPSC frequency recorded in non-EGFP interneurons $(\boldsymbol{E} ; n=9 ; p>0.05)$ or pyramidal cells $(\boldsymbol{F}$; $n=7 ; p>0.05)$. G, One-hundred nanomolars kainate did not alter the average amplitude of the mEPSCs recorded in EGFPexpressing SOM interneurons ( $p>0.05$ ). Top panels show example average EPSCs from an EGFP-expressing SOM interneuron recorded during control, kainate, and wash. $\boldsymbol{H}, \boldsymbol{I}$, Kainate also had no effect on the $\mathrm{mEPSC}$ amplitude in non-EGFP interneurons $(\boldsymbol{H} ;$ $p>0.05)$, or pyramidal cells (I; $p>0.05)$. Calibration: $\boldsymbol{D}, 10 \mathrm{pA}, 5 \mathrm{~s} ; \boldsymbol{E}, \boldsymbol{F}, 10 \mathrm{pA}, 2 \mathrm{~s} ; \boldsymbol{G}, 10 \mathrm{pA}, 10 \mathrm{~ms} ; \boldsymbol{H}, \boldsymbol{I}, 10 \mathrm{pA}, 10 \mathrm{~ms}$.

effect on the MK-801 decay curves of either pyramidal cells (Fig. $5 B)(\tau=52.0 \pm 4.7$ vs $63.6 \pm 10.7$; Student's $t$ test, $p>0.05 ; n=$ $6)$ or non-EGFP interneurons (Fig. $5 C)(\tau=25.5 \pm 5.0$ vs $27.5 \pm$ 9.1; Student's $t$ test, $p>0.05 ; n=9)$.

To further confirm that kainate receptor activation is acting presynaptically to increase release probability, we compared the frequency and amplitude of mEPSCs (recorded in $1 \mu \mathrm{M}$ TTX) before and during application of $100 \mathrm{~nm}$ kainate. Figure 5D (top) shows example traces of mEPSCs recorded from an EGFPexpressing SOM interneuron in control, during kainate application, and after kainate washout. Bath application of kainate caused an increase in the mEPSC frequency in EGFP-expressing SOM interneurons (Fig. 5D, bottom) $(p<0.05 ; n=8)$, which was reversed after washout of kainate $(p<0.05 ; n=5)$. There was no change in the average mEPSC amplitude, as shown in Figure $5 G(p>0.05)$, indicating that the effect of the kainate receptors was only presynaptic. The effect was selective for EGFP-expressing SOM interneurons, because bath application of $100 \mathrm{~nm}$ kainate had no effect on the mEPSC frequency of non-EGFP interneurons (Fig. $5 E)(p>0.05 ; n=9)$ or pyramidal cells (Fig. $5 F)(p>0.05 ; n=7)$. There was also no effect of kainate on their average mEPSC amplitudes (Fig. 5H,I) $(p>0.05)$.

Together, our results show that kainate receptor activation is acting presynaptically to increase the probability of release, and that the mechanism is specific to Schaffer collateral synapses onto EGFPexpressing SOM interneurons.

\section{Model fits large facilitation of synapses onto EGFP-expressing SOM \\ interneurons with a low initial release probability and presynaptic facilitation of release by synaptic activation of kainate receptors}

Finally, we tested whether our model was able to fit the data for the EGFPexpressing SOM interneurons if we modified it to include a mechanism for the facilitation of glutamate release by synaptically released glutamate acting at presynaptic kainate receptors. Although the exact mechanism by which kainate receptor activation increases release probability is not known, we were able to get a good fit when we added a parameter $\left(\Delta_{K A R}\right)$ that increased facilitation by providing an additional increase in the release probability per vesicle after action potential stimulation (see Appendix). This parameter was set to a value of 5 (normalized) for simulations of control data for EGFP-expressing SOM interneurons, and set to 0 for simulations of data with NS102 (presynaptic kainate receptors blocked) (Table 1). This enabled the model to simultaneously fit both the paired-pulse (Fig. 6A) and five-pulse data (Fig. $6 B$ ), for both control (black) and NS-102 (gray), while keeping the values of the initial release probability per vesicle $\left(\alpha_{1}=\right.$ $0.025)$ and initial readily releasable pool size $\left(n_{T}=5.0\right)$ the same for all four experimental conditions (Table 1). This results in an initial release probability $P_{1}=0.12$ that is lower than the model values for non-EGFP interneurons $\left(P_{1}=0.52\right)$ or pyramidal cells $\left(P_{1}=0.17\right)$. The low initial release probability predicted by the model is in agreement with the very slow block by MK-801 for the EGFP-expressing SOM interneurons (Figs. 2, 5A, control). All other model parameters were kept the same as for pyramidal cells and non-EGFP interneurons (Table 2). The model is able to quantitatively account for the large paired-pulse and five-pulse facilitation at synapse onto EGFP-expressing SOM interneurons by the combination of the two mechanisms we observed experi- 


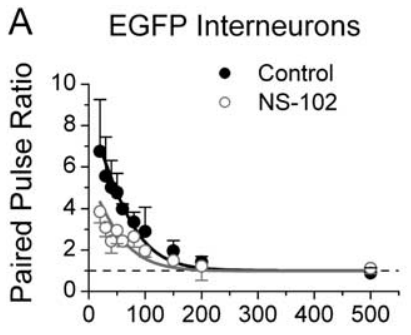

Paired Pulse Interval (ms)
B

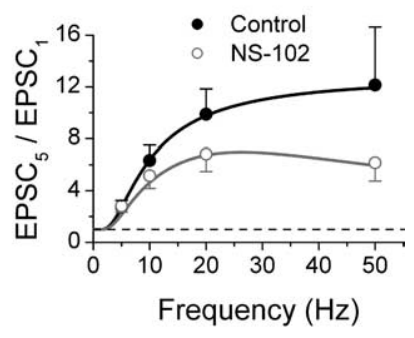

Figure 6. Model that includes an additional mechanism for kainate receptor induced facilitation now fits data from EGFP-expressing SOM interneurons. $A, B$, Mathematical model of short-term plasticity which includes a mechanism for kainate receptor mediated facilitation $\left(\Delta_{\text {KAR }}=5\right)$ provides good fit (black lines) to both paired-pulse $(\boldsymbol{A})$ and five-pulse $(\boldsymbol{B})$ data for synapses onto EGFP-expressing SOM interneurons in control (black circles). Eliminating this mechanism $\left(\Delta_{\text {KAR }}=0\right)$ and keeping all other parameters the same provides good fits (gray lines) to paired-pulse and five pulse data in NS-102 (open gray circles). Other than $\Delta_{\text {KAR }}$ all model parameters are the same as for pyramidal cells and non-EGFP interneurons (Table 2) except for the initial release probability per vesicle $\left(\alpha_{1}\right)$ and the initial readily releasable vesicle pool size $\left(n_{T}\right)$, which result in a lower initial release probability $\left(P_{1}=0.12\right)$ (Table 1).

mentally: a low initial release probability, and facilitation caused by synaptically released glutamate activating presynaptic kainate receptors to increase release probability on subsequent pulses. Although this does not rule out other possible mechanisms that could also contribute to facilitation at these synapses, it does suggest that the two mechanisms observed experimentally are sufficient to produce the large facilitation observed at Schaffer collateral synapses onto EGFP-expressing SOM interneurons.

\section{Discussion}

We have discovered a novel mechanism contributing to target cell-specific synaptic plasticity at Schaffer collateral synapses in the hippocampus. Unlike synapses onto the majority of interneurons in s. radiatum of CA1, synapses onto a subset of somatostatin interneurons have extremely large short-term facilitation. Previously, target-cell specificity of short-term plasticity has been attributed to differences in the initial release probability, both in the cortex (Rozov et al., 2001; Koester and Johnston, 2005) and in the hippocampus (Sun et al., 2005). Whereas a low initial release probability contributes to the facilitation, activation of kainate receptors by synaptically released glutamate increases release on subsequent pulses to enhance facilitation. This rapidly increases synaptic strength at these synapses during action-potential bursts, selectively potentiating them relative to other Schaffer collateral synapses.

We demonstrate the presence of kainate receptors in four separate experiments. We show that the kainate receptor antagonist NS-102 reduces short-term facilitation, and that blocking kainate receptors with DNQX reduces facilitation of NMDA EPSCs. Using the MK-801 method, we show that exogenous kainate increases the presynaptic release probability. In addition, exogenous kainate increases the frequency of mEPSCs. These effects were specific for Schaffer collateral synapses onto EGFPexpressing SOM interneurons in s. radiatum. There were no effect at synapses onto non-EGFP interneurons, which are most likely non-SOM interneurons because SOM interneurons in s. radiatum are rare (Freund and Buzsaki, 1996), or at synapses onto CA1 pyramidal cells. Together, these experiments show that synaptically released glutamate activates kainate receptors and increases release probability on subsequent pulses, contributing to the large short-term facilitation of Schaffer collateral synapses onto EGFP-expressing SOM interneurons.
This is a novel function for Schaffer collateral axons that occurs at only a subset of synapses based on their postsynaptic target. Although presynaptic kainate autoreceptors can increase facilitation at mossy fiber synapses in CA3 (e.g., Contractor et al., 2001), no such role had been described previously at any Schaffer collateral synapses. At Schaffer collateral synapses onto CA1 pyramidal cells, presynaptic kainate receptors instead depress glutamate release in response to high concentrations of exogenous agonists in juveniles (Frerking et al., 2001), or by tonic activation of high affinity receptors by ambient glutamate during the first postnatal week (Lauri et al., 2006). In juveniles, the depression of release occurs through low affinity receptors (Kamiya and Ozawa, 1998), whereas the facilitation of release at synapses onto EGFP-expressing SOM interneurons occurs via high-affinity receptors. It remains to be determined whether this results from differences in subunit composition, and if so, how different kainate receptors are targeted to axon terminals based on the postsynaptic neuron.

Because NS-102 is selective for kainate receptors containing the GluR6 subunit (for review, see Chittajallu et al., 1999), our results suggest that either homomeric GluR6 receptors or heteromeric receptors containing GluR6 underlie the kainate receptor effect. Similarly, the presynaptic kainate autoreceptors that increase facilitation at mossy fiber synapses contain GluR6 (Contractor et al., 2001; Breustedt and Schmitz, 2004) (but see Vignes et al., 1997). In addition, the depression of release at Schaffer collateral synapses onto CA1 pyramidal cells by exogenous kainate is antagonized by NS-102, suggesting a role for GluR6 kainate receptors (Kamiya and Ozawa, 1998), although it may also depend on kainate receptors containing GluR5 (Vignes et al., 1998; Clarke and Collingridge, 2002). Our results do not rule out a possible role for the GluR5 subunit in the facilitatory effect at Schaffer collateral synapses onto EGFP-expressing SOM interneurons, as GluR5 and GluR6 can form functional heteromeric receptors (Paternain et al., 2000). Although future studies are needed to precisely determine their subunit composition, our results show that synaptic activation of presynaptic kainate receptors enhances short-term facilitation at these synapses.

We showed previously that Schaffer synapses onto s. radiatum interneurons in slices from rat have lower facilitation and faster MK-801 block than synapses onto pyramidal cells (Sun et al., 2005). This is also true for the non-EGFP interneurons studied here, suggesting that Schaffer collateral synapses onto most s. radiatum interneurons have a higher release probability than synapses onto pyramidal cells in both rats and GIN mice. In contrast, Schaffer collateral synapses onto EGFP-expressing SOM interneurons in GIN mice have large facilitation and a slow MK-801 blocking rate that increased with bath-applied kainate, suggesting they instead have a low release probability. Furthermore, although blocking kainate receptors reduces short-term facilitation at these synapses, facilitation remains even in the presence of the blockers, also consistent with low release probability. Their lower mEPSC rate also suggests a low release probability, although differences in synapse number cannot be ruled out. Together, these experiments strongly suggest that Schaffer collateral synapses onto EGFP-expressing SOM interneurons have a low release probability, in contrast to the higher probability at synapses onto most s. radiatum interneurons.

The inability of our original mathematical model (Sun et al., 2005 ) to fit the data for synapses onto EGFP-expressing SOM interneurons with only a decrease in release probability led us to consider that an additional mechanism might contribute to the large short-term facilitation at these unique synapses. This pre- 
diction was confirmed by subsequent experiments, illustrating the power of combining experiments with modeling. Our experiments show that kainate receptor activation acts presynaptically to increase release probability and enhance short-term facilitation. Incorporating this mechanism into our mathematical model enabled it to simultaneously fit the control data for pairedpulse and five-pulse facilitation using the same parameters, as it had for pyramidal cell and non-EGFP interneurons. Although the exact mechanism by which kainate receptor activation increases release probability is unknown, our model fit the data by incorporating a calcium-dependent increase in the release probability per vesicle. This could occur directly because of calcium influx through calcium-permeable kainate receptors (Lauri et al., 2003), or indirectly through depolarization causing increased action potential calcium influx (Kamiya, 2002; Kamiya et al., 2002). Although the model may need additional refinement once we determine how kainate receptors increase release probability, the simulations show that a low initial release probability combined with the synaptically stimulated increase in release are sufficient to account for the large facilitation at these synapses.

Although virtually all EGFP interneurons in hippocampus of GIN mice express somatostatin, they are a subset of somatostatin-containing interneurons (Oliva et al., 2000). The EGFP interneurons may be a specialized subset of somatostatin interneurons based on the presence (or lack) of an additional neurochemical marker. It remains to be determined if the nonEGFP somatostatin-expressing interneurons in s. radiatum also have synaptic inputs with large facilitation, indicating that this is a general feature of Schaffer collateral synapses onto somatostatin interneurons, or little or no facilitation like the non-EGFP interneurons that we studied here. All EGFP-expressing SOM interneurons tested in s. radiatum had large short-term facilitation, supporting our hypothesis that functional properties such as short-term plasticity of excitatory inputs are different for subgroups of interneurons identifiable by neurochemical content. The EGFP-expressing SOM interneurons in s. radiatum could still be heterogeneous, rather than one unique subtype, as has been suggested for cortical EGFP-expressing interneurons in GIN mice (Ma et al., 2006).

Somatostatin-containing interneurons in other areas also show paired-pulse facilitation. In s. oriens, a subset of interneurons called O-LM cells project to s. lacunosum-moleculare (s. LM), most of which contain somatostatin and have facilitating inputs from CA1 pyramidal cells (Losonczy et al., 2002). Similarly, bitufted interneurons in cortex, many of which contain somatostatin, have facilitating inputs (Reyes et al., 1998). We also see large paired-pulse facilitation at Schaffer collateral synapses onto EGFP-expressing interneurons in s. pyramidale and s. oriens in GIN mice (our unpublished observations). It remains to be determined whether presynaptic kainate receptors also contribute to short-term facilitation at excitatory synapses onto somatostatin-containing interneurons in these other regions.

Morphologically, EGFP-expressing SOM interneurons with somata in s. radiatum of CA1 are called R-LM cells because of their extensive axonal arborization in s. LM (Oliva et al., 2000). Because s. LM receives direct excitatory input to CA1 from entorhinal cortex via the temporoammonic pathway (Amaral, 1993), these cells are likely to be important in regulating information flow through hippocampus. Both R-LM and O-LM cells may act as "input-biasing" interneurons, whose firing will produce inhibitory input to s. LM that can filter out information from the entorhinal cortex (Oliva et al., 2000). However, R-LM cells receive their excitatory inputs primarily from CA3 pyramidal cells, whereas O-LM cells are innervated by CA1 pyramidal cells. Thus, R-LM cells are poised to selectively inhibit entorhinal input to CA1 pyramidal cells in response to input from CA3 (Oliva et al., 2000).

Furthermore, the unique properties of the Schaffer collateral inputs to the EGFP-expressing SOM interneurons may enable them to function as burst detectors. Although their low initial probability of release may fail to drive firing during lowfrequency stimulation, the large short-term facilitation will likely recruit these cells to fire during bursts. This may selectively increase inhibition to distal dendrites of CA1 pyramidal cells, suppressing the temporoammonic pathway, while short-term facilitation enhances excitation onto proximal dendrites of CA1 pyramidal cells. This provides a novel mechanism for fine-tuning the function of hippocampal circuits, and demonstrates another role for presynaptic kainate receptors in filtering information in hippocampus.

\section{Appendix: A mathematical description for short-term synaptic plasticity}

We have previously developed a mathematical description of short-term plasticity (Sun et al., 2005) that incorporated features of several previous models (Dobrunz and Stevens, 1997; Tsodyks et al., 1998; Dittman et al., 2000; Dobrunz, 2002). The model contains three possible states for a synapse: release-ready $(x(t))$, releasing $(y(t))$, and refractory $(z(t))$. Only synapses in the release-ready state are capable of releasing a vesicle when an action potential arrives (Tsodyks et al., 1998). Facilitation results from the enhancement of average release probability $P(t)$, which is determined by average release probability per vesicle $\alpha(t)$ and the readily releasable vesicle pool size $n(t)$. Depression results from depletion of the readily releasable vesicle pool (Dobrunz and Stevens, 1997; Dobrunz, 2002) and from synapses becoming refractory after release (Dobrunz et al., 1997; Tsodyks et al., 1998). The corresponding kinetic equations are as follows:

$$
\begin{gathered}
\frac{d x}{d t}=\frac{z(t)}{\tau_{\text {rec }}}-P(t) \times x(t) \times \delta\left(t-t_{\mathrm{ap}}\right) \\
\frac{d y}{d t}=P(t) \times x(t) \times \delta\left(t-t_{\mathrm{ap}}\right)-\frac{y(t)}{\tau_{\text {in }}} \\
\frac{d z}{d t}=\frac{y(t)}{\tau_{\text {in }}}-\frac{z(t)}{\tau_{\text {rec }}} \\
\frac{1}{\tau_{\text {rec }}}=\frac{k_{\text {max }}-k_{0}}{1+K_{D} / C a X_{D}(t)}+k_{0} \\
\frac{d C a X_{D}}{d t}=\left(-C a X_{D}(t) / \tau_{D}\right)+\Delta_{D} \times \delta\left(t-t_{\text {ap }}\right) \\
P(t)=1-(1-\alpha(t))^{n(t)} \\
\alpha(t)=\alpha+\frac{1-\alpha_{1}}{1+K_{F} / C a X_{F}(t)} \\
\frac{d C a X_{F}}{d t}=\left(-C a X_{F}(t) / \tau_{F}\right)+\Delta_{F} \times \delta\left(t-t_{\text {ap }}\right) \\
P(t) \times x(t) \times \delta\left(t-t_{\mathrm{ap}}\right)+\left(n_{T}-n(t)\right) \times R \quad n \leq n_{T},
\end{gathered}
$$


where $\delta$ is the Dirac $\delta$ function, and $t_{a p}$ is the time of occurrence of an action potential. $P(t)$ is the average release probability. The time constant of recovery from the refractory state $\left(\tau_{\text {rec }}\right)$ is assumed to be calcium-dependent and determined by the equilibrium binding occupancy of a calcium-bound molecule $\mathrm{CaX} \mathrm{X}_{D}$ (Dittman et al., 2000). $K_{D}$ is the dissociation parameter of calcium-bound molecule $C a X_{D}$, and $k_{\max }$ and $k_{0}$ are equilibrium constants; $\Delta_{D}$ is the amount $C a X_{D}$ increases after an action potential and $\tau_{D}$ is the decay constant of $\mathrm{CaX} \mathrm{X}_{D} ; n(t)$ is average readily releasable vesicle pool size and $n_{T}$ is its initial (maximum) value; $\alpha(t)$ is the average vesicular release probability, which is calcium dependent and determined by calcium-bound molecule $\mathrm{CaX}{ }_{F}, \alpha_{1}$ is the initial average vesicle release probability of an individual synapse. $K_{F}$ is the dissociation parameter of $C a X_{F} . \Delta_{F}$ is an increase in $C a X_{F}$ after an action potential and $\tau_{F}$ is the decay constant; $R$ is the refilling rate of the readily releasable pool. Details of the model derivation can be found in our previous paper (Sun et al., 2005).

To simulate data obtained from EGFP-expressing SOM interneurons (Fig. 6) the original model was modified to incorporate the effect of kainate receptor activation to increase release. Although the exact mechanism by which presynaptic kainate receptors increase release is not known, we have incorporated this effect into the model as an increase in the release probability per vesicle, caused by calcium binding to a molecule $\mathrm{Ca} \mathrm{X}_{\mathrm{KAR}}$, similar to the calcium bound molecule $C a X_{F}$ that causes facilitation. An additional term is added to the equation for $\alpha(t)$, resulting in the following:

$$
\alpha(t)=\alpha_{1}+\frac{1-\alpha_{1}}{1+K_{F} /\left(\operatorname{CaX} X_{F}(t)+\operatorname{CaX}_{\mathrm{KAR}}(t)\right)},
$$

where

$$
\frac{d C a X_{\mathrm{KAR}}}{d t}=\left(-C a X_{\mathrm{KAR}}(t) / \tau_{\mathrm{KAR}}\right)+\Delta_{\mathrm{KAR}} \times \delta\left(t-t_{\mathrm{ap}}\right) .
$$

$\Delta_{\mathrm{KAR}}$ is the enhancement of calcium influx caused by kainate receptor activation. $\tau_{\mathrm{KAR}}$ is the decay constant of $\mathrm{CaX} \mathrm{KAR}_{\mathrm{KAR}}$. There is no evidence that $\mathrm{CaX} X_{F}$ and $\mathrm{CaX} \mathrm{XAR}_{\mathrm{KAR}}$ are the same calciumbinding molecule, so the model treats them as different molecules having different decay constants $\tau_{F}$ and $\tau_{\text {KAR }}$.

The paired-pulse ratio and five-pulse ratio can be computed by using the above equation group (Sun et al., 2005). There are 15 parameters in the model. Ten of them are constant for all synapses onto different cell types; the values of these parameters are given in Table 2. Five parameters are variables for synapses onto different cell types; their values are given in Table 1.

In the present study, all mathematical calculations were performed using Mathematica software (fourth edition, Wolfram Media, Champaign, IL).

\section{References}

Abbott LF, Varela JA, Sen K, Nelson SB (1997) Synaptic depression and cortical gain control. Science 275:220-224.

Ali AB, Deuchars J, Pawelzik H, Thomson AM (1998) CA1 pyramidal to basket and bistratified cell EPSPs: dual intracellular recordings in rat hippocampal slices. J Physiol (Lond) 507:201-217.

Allen C, Stevens CF (1994) An evaluation of causes for unreliability of synaptic transmission. Proc Natl Acad Sci USA 91:10380-10383.

Amaral DG (1993) Emerging principles of intrinsic hippocampal organization. Curr Opin Neurobiol 3:225-229.

Avignone E, Frenguelli BG, Irving AJ (2005) Differential responses to NMDA receptor activation in rat hippocampal interneurons and pyramidal cells may underlie enhanced pyramidal cell vulnerability. Eur J Neurosci 22:3077-3090.
Bahring R, Bowie D, Benveniste M, Mayer ML (1997) Permeation and block of rat GluR6 glutamate receptor channels by internal and external polyamines. J Physiol (Lond) 502:575-589.

Breustedt J, Schmitz D (2004) Assessing the role of GLUK5 and GLUK6 at hippocampal mossy fiber synapses. J Neurosci 24:10093-10098.

Castro-Alamancos MA, Connors BW (1997) Distinct forms of short-term plasticity at excitatory synapses of hippocampus and neocortex. Proc Natl Acad Sci USA 94:4161-4166.

Chavis P, Westbrook G (2001) Integrins mediate functional pre- and postsynaptic maturation at a hippocampal synapse. Nature 411:317-321.

Chen N, Luo T, Raymond LA (1999) Subtype-dependence of NMDA receptor channel open probability. J Neurosci 19:6844-6854.

Chittajallu R, Braithwaite SP, Clarke VR, Henley JM (1999) Kainate receptors: subunits, synaptic localization and function. Trends Pharmacol Sci 20:26-35.

Christensen JK, Paternain AV, Selak S, Ahring PK, Lerma J (2004) A mosaic of functional kainate receptors in hippocampal interneurons. J Neurosci 24:8986-8993.

Clarke VR, Collingridge GL (2002) Characterisation of the effects of ATPA, a GLU(K5) receptor selective agonist, on excitatory synaptic transmission in area CA1 of rat hippocampal slices. Neuropharmacology 42:889-902.

Contractor A, Swanson G, Heinemann SF (2001) Kainate receptors are involved in short- and long-term plasticity at mossy fiber synapses in the hippocampus. Neuron 29:209-216.

Dittman JS, Kreitzer AC, Regehr WG (2000) Interplay between facilitation, depression, and residual calcium at three presynaptic terminals. J Neurosci 20:1374-1385.

Dobrunz LE (2002) Release probability is regulated by the size of the readily releasable vesicle pool at excitatory synapses in hippocampus. Intl J Dev Neurosci 20:225-236.

Dobrunz LE, Stevens CF (1997) Heterogeneity of release probability, facilitation, and depletion at central synapses. Neuron 18:995-1008.

Dobrunz LE, Huang EP, Stevens CF (1997) Very short-term plasticity in hippocampal synapses. Proc Natl Acad Sci USA 94:14843-14847.

Flint AC, Maisch US, Weishaupt JH, Kriegstein AR, Monyer H (1997) NR2A subunit expression shortens NMDA receptor synaptic currents in developing neocortex. J Neurosci 17:2469-2476.

Frerking M, Malenka RC, Nicoll RA (1998) Synaptic activation of kainate receptors on hippocampal interneurons. Nat Neurosci 1:479-486.

Frerking M, Schmitz D, Zhou Q, Johansen J, Nicoll RA (2001) Kainate receptors depress excitatory synaptic transmission at CA3 $\rightarrow$ CA1 synapses in the hippocampus via a direct presynaptic action. J Neurosci 21:2958-2966.

Freund TF, Buzsaki G (1996) Interneurons of the hippocampus. Hippocampus 6:347-470.

Hardingham NR, Larkman AU (1998) The reliability of excitatory synaptic transmission in slices of rat visual cortex in vitro is temperature dependent. J Physiol (Lond) 507:249-256.

Hollmann M, Heinemann S (1994) Cloned glutamate receptors. Annu Rev Neurosci 17:31-108.

Huang EP, Stevens CF (1997) Estimating the distribution of synaptic reliabilities. J Neurophysiol 78:2870-2880.

Ji Z, Staubli U (2002) Presynaptic kainate receptors play different physiological roles in mossy fiber and associational-commissural synapses in CA3 of hippocampus from adult rats. Neurosci Lett 331:71-74.

Kamiya H (2002) Kainate receptor-dependent presynaptic modulation and plasticity. Neurosci Res 42:1-6.

Kamiya H, Ozawa S (1998) Kainate receptor-mediated inhibition of presynaptic $\mathrm{Ca}^{2+}$ influx and EPSP in area CA1 of the rat hippocampus. J Physiol (Lond) 509:833-845.

Kamiya H, Ozawa S, Manabe T (2002) Kainate receptor-dependent shortterm plasticity of presynaptic $\mathrm{Ca}^{2+}$ influx at the hippocampal mossy fiber synapses. J Neurosci 22:9237-9243.

Klyachko VA, Stevens CF (2006) Temperature-dependent shift of balance among the components of short-term plasticity in hippocampal synapses. J Neurosci 26:6945-6957.

Koester HJ, Johnston D (2005) Target cell-dependent normalization of transmitter release at neocortical synapses. Science 308:863-866.

Laezza F, Doherty JJ, Dingledine R (1999) Long-term depression in hippocampal interneurons: joint requirement for pre- and postsynaptic events. Science 285:1411-1414.

Lauri SE, Delany C, VR JC, Bortolotto ZA, Ornstein PL, J TRI, Collingridge 
GL (2001) Synaptic activation of a presynaptic kainate receptor facilitates AMPA receptor-mediated synaptic transmission at hippocampal mossy fibre synapses. Neuropharmacology 41:907-915.

Lauri SE, Bortolotto ZA, Nistico R, Bleakman D, Ornstein PL, Lodge D, Isaac JT, Collingridge GL (2003) A role for $\mathrm{Ca}^{2+}$ stores in kainate receptordependent synaptic facilitation and LTP at mossy fiber synapses in the hippocampus. Neuron 39:327-341.

Lauri SE, Vesikansa A, Segerstrale M, Collingridge GL, Isaac JT, Taira T (2006) Functional maturation of CA1 synapses involves activitydependent loss of tonic kainate receptor-mediated inhibition of glutamate release. Neuron 50:415-429.

Lei S, McBain CJ (2002) Distinct NMDA receptors provide differential modes of transmission at mossy fiber-interneuron synapses. Neuron 33:921-933.

Losonczy A, Zhang L, Shigemoto R, Somogyi P, Nusser Z (2002) Cell type dependence and variability in the short-term plasticity of EPSCs in identified mouse hippocampal interneurones. J Physiol (Lond) 542:193-210.

Ma Y, Hu H, Berrebi AS, Mathers PH, Agmon A (2006) Distinct subtypes of somatostatin-containing neocortical interneurons revealed in transgenic mice. J Neurosci 26:5069-5082.

Markram H, Wang Y, Tsodyks M (1998) Differential signaling via the same axon of neocortical pyramidal neurons. Proc Natl Acad Sci USA 95:5323-5328.

McBain CJ (1998) A short-term mechanism of plasticity for interneurones? J Physiol (Lond) 511:331.

Micheva KD, Smith SJ (2005) Strong effects of subphysiological temperature on the function and plasticity of mammalian presynaptic terminals. J Neurosci 25:7481-7488.

Mulle C, Sailer A, Swanson GT, Brana C, O'Gorman S, Bettler B, Heinemann SF (2000) Subunit composition of kainate receptors in hippocampal interneurons. Neuron 28:475-484.

Oliva Jr AA, Jiang M, Lam T, Smith KL, Swann JW (2000) Novel hippocampal interneuronal subtypes identified using transgenic mice that express green fluorescent protein in GABAergic interneurons. J Neurosci 20:3354-3368.

Paternain AV, Morales M, Lerma J (1995) Selective antagonism of AMPA receptors unmasks kainate receptor-mediated responses in hippocampal neurons. Neuron 14:185-189.

Paternain AV, Vicente A, Nielsen EO, Lerma J (1996) Comparative antagonism of kainate-activated kainate and AMPA receptors in hippocampal neurons. Eur J Neurosci 8:2129-2136.

Paternain AV, Herrera MT, Nieto MA, Lerma J (2000) GluR5 and GluR6 kainate receptor subunits coexist in hippocampal neurons and coassemble to form functional receptors. J Neurosci 20:196-205.

Pyott SJ, Rosenmund C (2002) The effects of temperature on vesicular supply and release in autaptic cultures of rat and mouse hippocampal neurons. J Physiol (Lond) 539:523-535.
Reyes A, Lujan R, Rozov A, Burnashev N, Somogyi P, Sakmann B (1998) Target-cell-specific facilitation and depression in neocortical circuits. Nat Neurosci 1:279-285.

Rozov A, Burnashev N (1999) Polyamine-dependent facilitation of postsynaptic AMPA receptors counteracts paired-pulse depression. Nature 401:594-598.

Rozov A, Burnashev N, Sakmann B, Neher E (2001) Transmitter release modulation by intracellular $\mathrm{Ca}^{2+}$ buffers in facilitating and depressing nerve terminals of pyramidal cells in layer $2 / 3$ of the rat neocortex indicates a target cell-specific difference in presynaptic calcium dynamics. J Physiol (Lond) 531:807-826.

Scanziani M, Gahwiler BH, Charpak S (1998) Target cell-specific modulation of transmitter release at terminals from a single axon. Proc Natl Acad Sci USA 95:12004-12009.

Schmitz D, Mellor J, Nicoll RA (2001) Presynaptic kainate receptor mediation of frequency facilitation at hippocampal mossy fiber synapses. Science 291:1972-1976.

Standaert DG, Landwehrmeyer GB, Kerner JA, Penney Jr JB, Young AB (1996) Expression of NMDAR2D glutamate receptor subunit mRNA in neurochemically identified interneurons in the rat neostriatum, neocortex and hippocampus. Brain Res Mol Brain Res 42:89-102.

Stocca G, Vicini S (1998) Increased contribution of NR2A subunit to synaptic NMDA receptors in developing rat cortical neurons. J Physiol (Lond) 507:13-24.

Sun HY, Lyons SA, Dobrunz LE (2005) Mechanisms of target-cell specific short-term plasticity at Schaffer collateral synapses onto interneurones versus pyramidal cells in juvenile rats. J Physiol (Lond) 568:815-840.

Thomson AM (1997) Activity-dependent properties of synaptic transmission at two classes of connections made by rat neocortical pyramidal axons in vitro. J Physiol (Lond) 502:131-147.

Toth K, Suares G, Lawrence JJ, Philips-Tansey E, McBain CJ (2000) Differential mechanisms of transmission at three types of mossy fiber synapse. J Neurosci 20:8279-8289.

Tsodyks M, Pawelzik K, Markram H (1998) Neural networks with dynamic synapses. Neural Comput 10:821-835.

Vignes M, Bleakman D, Lodge D, Collingridge GL (1997) The synaptic activation of the GluR5 subtype of kainate receptor in area CA3 of the rat hippocampus. Neuropharmacology 36:1477-1481.

Vignes M, Clarke VR, Parry MJ, Bleakman D, Lodge D, Ornstein PL, Collingridge GL (1998) The GluR5 subtype of kainate receptor regulates excitatory synaptic transmission in areas CA1 and CA3 of the rat hippocampus. Neuropharmacology 37:1269-1277.

Wilding TJ, Huettner JE (1996) Antagonist pharmacology of kainate- and alpha-amino-3-hydroxy-5-methyl-4-isoxazolepropionic acid-preferring receptors. Mol Pharmacol 49:540-546.

Zucker RS, Regehr WG (2002) Short-term synaptic plasticity. Annu Rev Physiol 64:355-405. 